\title{
ANAL YSIS OF THE ONGOING TRANSFORMATION OF VERNACULAR ARCHITECTURE IN LA SAGRA REGION, TOLEDO, SPAIN
}

\author{
A. Garcia Hermida $1, *$ \\ ${ }^{1}$ Departamento de Composición Arquitectónica, Escuela Técnica Superior de Arquitectura (ETSAM), Universidad Politécnica de \\ Madrid (UPM) - alejandro.garcia.hermida@upm.es
}

Commission II, WG - II/8

KEY WORDS: Vernacular architecture, Traditional architecture, Transformation, Local Identity, Building Patterns, Toledo

\begin{abstract}
:
We notice how the particular identities of the architectural tradition of our villages, towns and regions are suffering a historically unprecedented transformation, leading in some cases to its almost entire disappearance. In order to allow identifying the variables which are affecting these processes and to better address this problem a methodology has to be developed and systematically applied. Such a method has been developed for this study and tested in a specific case: La Sagra region in Toledo, where the transformations occurred in its vernacular architecture have been meticulously analysed. Using this tool, it has been possible to reliably identify those aspects having the most impact on the transformation of the architecture of this region. In order to do so, all existing buildings in a selected area, where all possible factors which might affect the studied phenomena were found to be homogeneous, have been studied, house after house and building detail after building detail: from their volume and composition to elements such as cornices, walls, roofs, lintels, windows, doors, finishings, chimneys, etc. This has allowed having accurate statistics on each and every transformation taking place: what is being replaced and how it is being replaced. These statistics are therefore scientifically showing the exact nature of the on-going transformations as well as, consequently, they are pointing out the most valuable ways to ease or even to stop the loss of local identity they are causing.
\end{abstract}

\section{INTRODUCTION}

Local architectural identities seem to be progressively vanishing or homogenising all over the world. Even the most protected and looked after urban complexes seem to be suffering these phenomena. Traditional building details and materials, along with their textures and colours are being lost even in those places where any change in the overall composition of the buildings or their façades is strictly banned. This deviation from the pursued aims to the obtained outcome is reflected in numerous contemporary debates, projects, publications and regulations (Instituto de Patrimonio Cultural de España, 2014).

Nevertheless, there are hardly any studies dealing with this subject, and, in order to face this problem in a sufficiently rigorous way, it is necessary to understand, first of all, how those identities we seek for preserving are being transformed, which factors are influencing these processes and to what extent they have an impact on them (Rapoport, 1969; Oliver, 2006), and how are they affected by the regulations nowadays in force to fight this kind of phenomena. To develop and test a useful method to provide an answer to these questions has been the aim of this research, and the method has been tested studying the case of La Sagra region in Toledo.

The selection of this area, given its location between the cities of Madrid and Toledo, allows studying built areas which transformation has been singularly intense in recent times but, yet their local tradition has not been erased by the urban processes affecting the nearest towns to Madrid. In order to keep that tradition different regulations have been passed over the years, conditioning in more or less details most of the alterations occurred. Therefore, there is in La Sagra a still comprehensible architectural identity, a series of tools which are or have been in place to preserve it, and a significant number of architectural transformations that have been testing them during the last years.

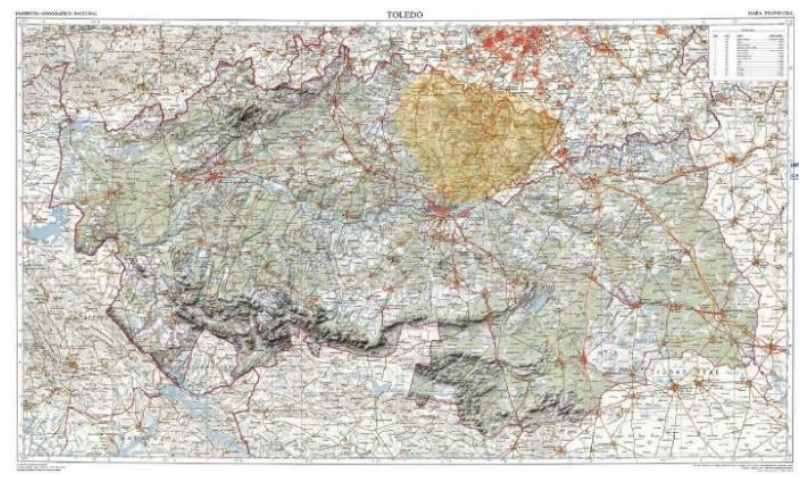

Figure 1. Location of La Sagra within the Toledo province (Base Plan: Instituto Geográfico Nacional, 2015)

In detail, the main aims of this research are the following: a. to study the contemporary evolution of the architectural and building patterns defining traditional local identity in the studied area, both in its historic and in its new buildings; b. to develop a method for it allowing scientifically quantifying and analysing the extent of those changes, one which can afterwards be adopted or adapted to study other contexts; c. to identity the key parameters affecting those processes, such as building types or building elements more keen to be transformed; d. to compare the impact of the identified transformations with the existing local regulations addressed to control them; and e. to search for possible principles or criteria which, in case to be found, could lead to obtaining better results in this field or be useful for the future architectural and building practice.

\footnotetext{
* Corresponding author
} 


\section{STUDIED CASE AND METHODOLOGY}

La Sagra belongs to two different autonomous territories: Madrid and Castilla-La Mancha, each of them having different circumstances and regulations affecting the studied matter. This difference would distort the results of this research, so it has been avoided in the selection of the towns of La Sagra for this study. Besides, the heterogeneity of the architectural and building traditions of La Sagra has proved to be a factor which would also distort the results of the study. The unexpected richness of diversity of the local tradition had never been studied to date, though they cannot be exposed in this paper due to its limited extension. In any case this knowledge has been an indirect outcome of this work.

Azorín was the first author in paying attention to the character of the towns of this region through his picturesque descriptions of one of its towns, Esquivias, from 1944 (2004: p. 7-8). Leopoldo Torres Balbás already worked specifically in defining the architectural identity of this area, including a chapter on the traditional house of La Sagra in his seminal work La vivienda popular en España (1933: p. 443-444). Fernando García Mercadal, in La casa popular en España (1930: p. 79-73), included two appealing drawings of traditional buildings of another of its towns, Illescas. Finally, both Luis Feduchi (19741984: 5, p. 152-153) and Carlos Flores (1974-1977: 3, p. 415) in their extensive studies of the Spanish vernacular houses would highlight the singularities of La Sagra houses within the more general types of La Mancha, but could not look at them into detail, given the national scope of their works, nor to address any of their most local specificities. Finally the last works which have dealt with the architecture of this area are those by Luis Cervera Vera on its main squares, Plazas mayores en la comarca toledana de La Sagra (1998), and by Antonio Sánchez-Horneros Gómez on the vernacular architecture of the province of Toledo as a whole, including some references to La Sagra, "La arquitectura popular toledana" (1981).

Thanks to this research, once the region was studied in more detail, it could be found there were towns where all the typological (such as the access to the house through an enclosed front courtyard, with the main façade standing within it) and constructive (such as the brencas type of rammed earth walls) features which were till now considered to be characteristic from La Sagra can be found. Located in the heart of the region, this is the cases of towns such as Esquivias or Illescas.

At the same time, a number of local singularities could be identified, mainly in particular building details and materials, especially regarding its walls. This way, for instance, in Cabañas de la Sagra rubble walls are the most common feature, as well as the mixed walls using both rubble stone and brick works, which are also the most frequent type of walls in other towns of the area such as Yunclillos.

In spite of such building singularities being more common than any typological specificity, they also exist in some cases. Such is the case of Borox, where all its main manors have a particular layout around a central courtyard, even when constructively are similar to those in the close-by towns.

During the development of this research, local features such as the regular kind of walls in a town being simply made of brencas rammed earth, of a combination of brick and earth, or of rubble masonry proved to have had a significant impact in the way the buildings have been altered or preserved.
As it will be further explained later on, the cultural origin of many transformations occurred in the urban landscape make this kind of local variations a potential distortion for this study. In consequence, the selected cases for the in-depth study, those where the analysed transformations have to be compared to the existing regulations to guide them, should be typologically and constructively homogeneous.

Therefore a group of towns within La Sagra was selected for a more detailed study, towns where architectural and constructive traditions were previously found to be practically identical, and where, belonging to the same autonomous region, the same nonlocal regulations apply.

Given these premises, an area entirely located in the province of Toledo and formed by four towns with basically the same typological and constructive tradition, diverse from that of rest of the towns in the region, was identified: the southernmost stripe of the Sagra Baja, made of the towns of Bargas, Olias del Rey, Magan and Mocejon.

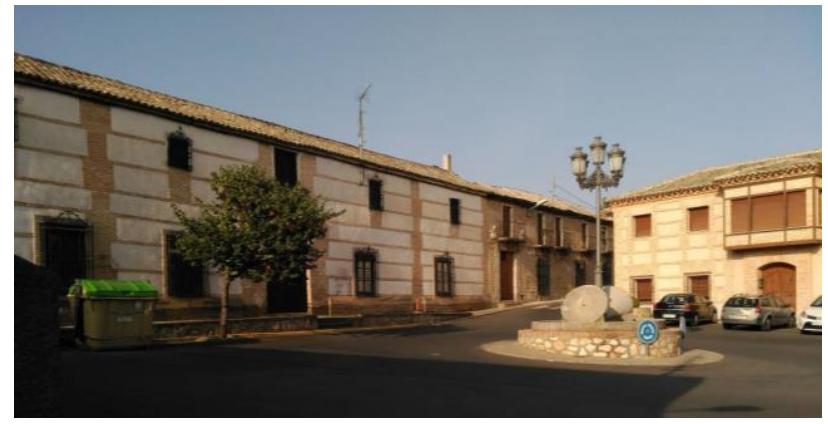

Figure 2. View of a square in Olias del Rey

Only a preliminary study of the existing traditional building techniques and architectural types in the entire region of La Sagra allowed making this selection.

The traditional walls of the houses in these four municipalities differ from those mainly used in the towns located further north. In the walls of their richest houses bricks and rammed earth are commonly combined. While there is almost no example of brencas rammed earth walls, those of their most humble houses are made of regular rammed earth or by combining adobe bricks and rammed earth. Full walls alternating courses of rubble and brick combined with rammed earth are also common in them, being this last building system also the most used one for the bases of any kind of walls. In the villages to the north of these four, such as Villaseca de la Sagra, regular rammed earth walls and walls combining brick and rammed earth become scarce, while the brencas rammed earth starts to prevail, this last type becoming further north almost the only existing kind of wall for any kind of house in the towns of the Sagra Alta.

After the general analysis of La Sagra, for each of the four selected municipalities an exhaustive field work was conducted. The existing architecture in each of their historic centres was studied building by building. Each house was photographed and documented, gathering specific data on its current situation and on the identified alterations on the traditional patterns. This way a series of quantified data were gathered for its subsequent comparative analysis.

Given it was the global situation of the local architectural identity what was going to be studied, these data should not belong only to the more or less preserved or transformed historic buildings, 
but also to the newly built architecture, for being also conditioned by the existing local regulations addressed to the preservation of local architectural identity in each of these towns.

The model of the data sheets to be used for gathering these data should thus be adapted to two different subjects: that of the historic buildings and that of the recent ones. For the historic buildings these sheets should focus on what had been preserved or transformed, as well as the nature of those transformations. For the new buildings they should include directly the extent of the use of local features in the way they were designed and built. After several tests, two different models of sheets were therefore adopted, but both designed in a way most of the parameters included in them could be jointly analysed afterwards.
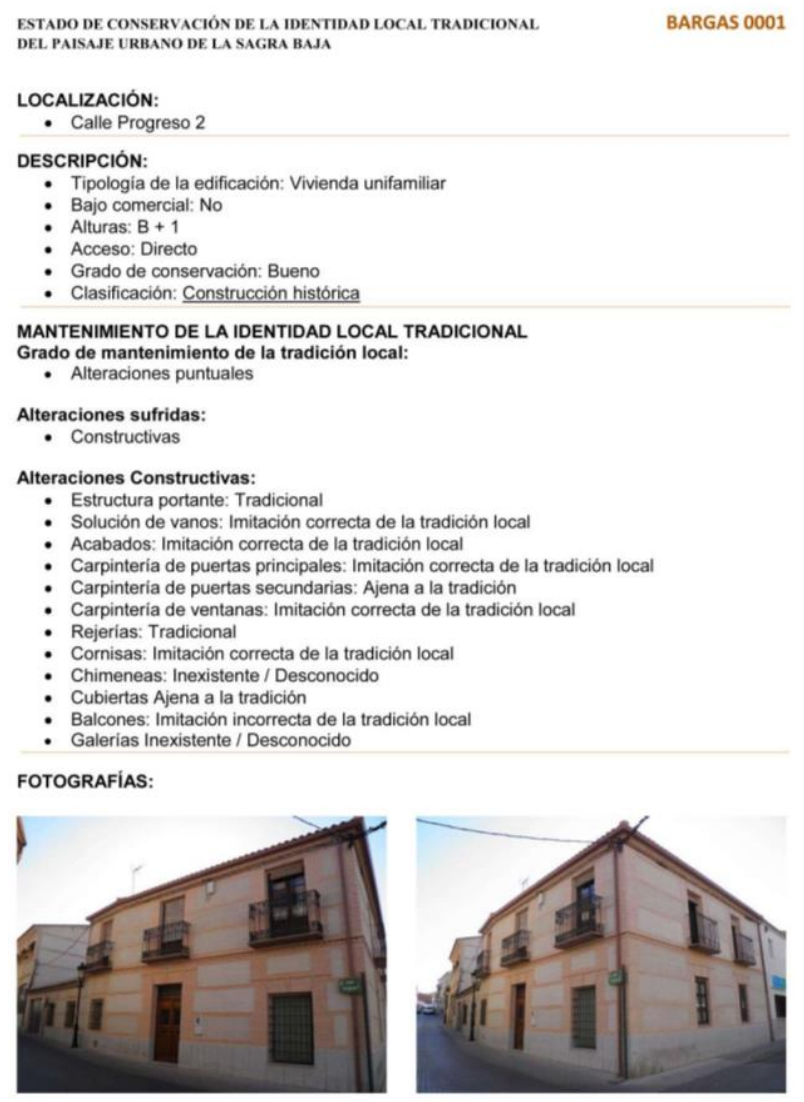

Figure 3. Sample of the data sheets used for historic buildings

The information these data sheets include on each house is firstly the following: a. one or two photographs of the building; $b$. its location; c. its description, including function (single-family house, condominium, public building, office building, mixed use, etc.), the type of access to the main façade of the building (directly from the street or through a traditional enclosed front patio), its number of floors, its state of conservation, etc. The chosen parameters were included since at the initial attempts to gather all needed data they soon proved to be linked to the kind of transformations suffered by the buildings, especially number of floors and type of access. From this description on, the gathered information differs, depending on being historic or recent buildings. Finally, for the analysis of how much each of the building details follows or departs from local tradition, exactly the same features are analysed for all buildings, so they can be easily related. These last features are only those which define the exterior look of the buildings, as those are the only ones which are restricted by local regulations in order to preserve local identity.
How much local tradition is kept (a. satisfactory, when almost no features or no significant ones have been transformed; b. partial alterations, when these are superficial and limited to specific features; and c. general alterations, when its volumes, overall composition or most building details have been modified in a non-traditional way) and the kind of alterations occurred (volume, overall composition, building details or none) are the only specific parameters for historic buildings.

As for recent buildings, it has been recorded how much a will to follow local tradition can be appreciated in them, independently of the outcome of that will (a. non-existent; b. limited to superficial features; c. extensive, including also volume and overall composition; and d. global), as well as the particular traditional features where a will to follow local tradition can be appreciated, once more without taking into account the quality of its outcome (in no feature, in building details, in volume, in composition, or in several of them).

After these specific parameters, the data which have been gathered are again the same for all buildings, though they relate to the nature of the transformations in each building feature in the case of historic buildings and to the more or less traditional character of the same elements in the case of recent buildings.

Having volume and composition features already been well documented through the specific previous parameters, particular transformations are analysed on the following building details: walls, lintels, finishings, main doors, secondary doors, windows, iron grilles, cornices, chimneys, roofs, balconies and wooden galleries or lookouts.

For each of these last elements it is noted if they are traditionally made, which not always means they are also historic; or, if not, if they have totally departed from tradition, or if they, even not being traditionally made, try to imitate somehow the traditional patterns. In this last case, it is noted if the imitated traditional patterns are exactly local or if they are just generically considered typical from Toledo or even foreign, and if the result of this imitation is satisfactory or not, in terms of the final image of it, which is what it is actually regulated nowadays in every town of La Sagra and in most Spanish towns.

The way to determine if local tradition was imitated in a satisfactory or unsatisfactory way requires a careful explanation. For instance, if a brick lintel is both designed and built in a traditional way it is noted as "traditional". When its look is that of a traditional brick lintel, but it is just a superficial veneer, with a different underlying structure, then there are several cases. If its look, which is the only currently regulated aspect, would allow taking it for a traditional one, being its appearance that of a correctly built brick lintel, and this was really a local traditional pattern, then it is noted as a "satisfactory imitation of local tradition". But the fact of this detail being a veneer allows for a number of "constructive" errors in its final appearance, once its image is detached from its structural role, so other cases are also possible, vulgar mockeries of the imitated detail. This is the case of brick lintels which pretend to look more or less traditional but are too low to look as if they actually worked, or where its brick voussoirs are all vertically placed or show awkward inclinations and therefore their placement would be impossible if they were really traditional details. These are the cases which are noted as "unsatisfactory imitations of local tradition". This is, there is clearly a will to make them look as traditional, as a brick veneer was added on the top of the actual structure, but the deficient outcome is also clearly showing they are just a poor fake. 
In order to clarify this even more, the example of the iron grilles can also be used. When these grilles are clearly tubular elements instead of solid iron and it is not even attempted to hide it, then they are noted as totally "non-traditional", as they show no will to conform to local tradition. If the grilles are all made of wrought-iron bars and all joints were forged, not using electric welding, they are noted as "traditional", independently of being new or historic details. If they are grilles looking like the traditional ones, where it would be complicated to tell from a certain distance if their joints are forged or not, then they are noted as "satisfactory imitations of local tradition". But if such imitations show inappropriate details, which would never work if having been actually forged, then they are noted as "unsatisfactory imitations of local traditions". This is the case of all grilles where the bars connecting the grille to the wall are incorrectly placed with regards to the position of the joints, or are directly screwed instead, and of all grilles where bars cross each other on the same plane, something impossible if really being traditional forged elements. Finally, if they are including foreign designs or elements, they are noted as "satisfactory imitations of foreign traditions" or "unsatisfactory imitations of foreign traditions" on the same terms as for the local ones.
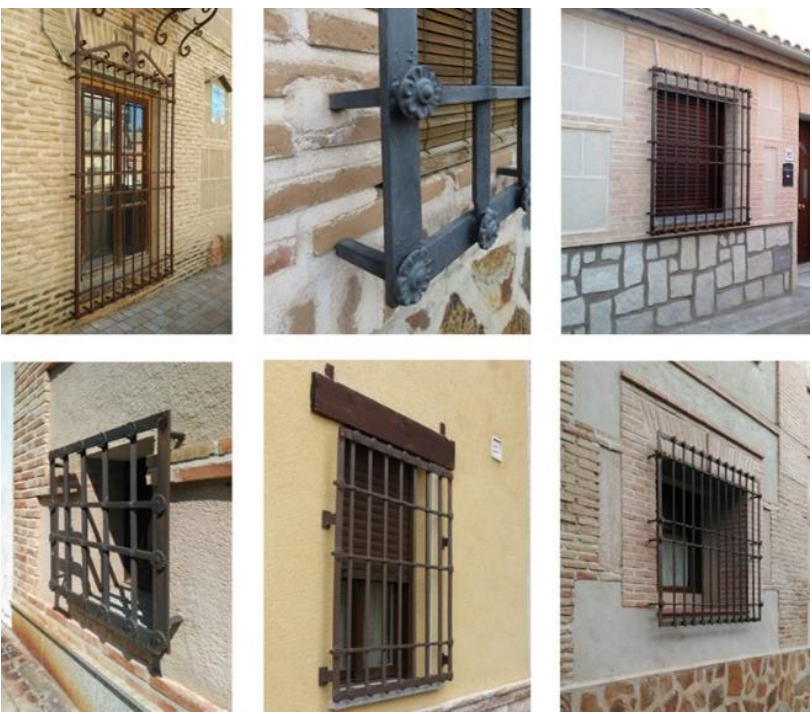

Figure 4. Examples of iron grilles noted as "satisfactory imitations of local tradition" on the top, and of those listed as "unsatisfactory imitations of local tradition" on the bottom

The same kind of wrong details are frequently found where traditional patterns are imitated for walls designed to look like having been built in a combination of brick and rammed earth, for wooden eaves, for the wooden joinery of doors and windows, etc. Most of these wrong details do meet what it is prescribed in the so-called "aesthetic conditions for buildings" set by the existing regulations of each town, as they very superficially focus on how each detail looks, imposing things as general as "roof tiles should be reddish", "exterior finishings should be in this or that colour", "grilles should be made of iron", etc.

A total of 2,274 data sheets were made. This corresponds to the total number of existing buildings in the historic centres of the four towns selected to be analysed in depth. They were 1,188 sheets for Bargas, 371 sheets for Olias del Rey, 232 sheets for Magan and 483 sheets for Mocejon.

Using these data diverse statistics on the on-going transformations could be produced, which were finally used to compare them to all other studied parameters and to the existing regulations on each particular feature in each town, in order to find out possible causes behind the existing transformation patterns. Some basic principles on them were sought, as well as any possible response to them which could enrich future regulations or practice.

\section{MAIN RESULTS}

Firstly, it is significant to have found in the four towns studied in depth a remarkably similar proportion of historic buildings which have been preserved, being also lower than expected. They are around a fourth of the buildings currently existing in their historic areas, being slightly more numerous in Olias del Rey than in the other towns. Besides, the less accurate visual observation made for the rest of La Sagra region allows to state the selected sample meets the average situation in the other municipalities of this very region, and similar results would be reached studying most of them. Those results would be especially lower, nevertheless, not in those of its towns located in the vicinity of Madrid or Toledo, nor in those with more real state pressure, but in those where their population by the mid of the $20^{\text {th }}$ century was significantly smaller, such as Yeles, Cobeja, Las Ventas de Retamosa or El Viso de San Juan. This is, in those where their local character was less urban or more humble just some decades ago. This is a very relevant fact. The deterioration of the local identity defined by traditional architecture is thus not so much conditioned by economic or technical aspects as by the more or less humble character of the buildings composing it, closely linked to the way local community perceives them.

The impact of this factor is better understood when the type of historic architecture still preserved and which buildings have especially tended to disappear are analysed. In La Sagra traditionally the lower houses were considered to be more humble, while the richest ones were commonly higher. They also differ in many other details, such as the constructive elements found in each of these types, which have a more vernacular character in the low houses. The height of the buildings was therefore linked to their social status. The number of the preserved large manors, those having more than just one floor, is nowadays slightly over the number of those more humble houses still kept, those having only the ground floor. In the historic photographs of this region it is clear that proportion is not the one existing in the past, when large neighbourhoods made of humble houses existed. These last ones were the prevailing type even to a greater extent in those towns which were less urban or less populated, exactly those where their traditional identity is today more altered. The larger manor houses have therefore been more regularly preserved than the smaller and more vernacular houses. They have not been listed till very recent times and only in some municipalities, so this fact could only be explained through economic aspects, such as the land value leading to prioritising those houses with more floors, or as a matter of social status. Nevertheless, the large houses lots are actually less densely built, for having wider courts and farmyards, and therefore more attractive for redevelopment. Thus the cultural perception of each type of house remains as the key explanation.

The proportion of still preserved historic houses having an indirect access from the street, this is, those accessed through the typical front courts of La Sagra, is also relevant for understanding the transformations which are taking place. In them, the main façade, regularly the richest and most representative one in every building, faces the private front court, and not the public realm. The presence of this type among the preserved historic buildings is remarkable and constitutes one of the most characteristic patterns in the urban landscape of La Sagra, but it is progressively 
disappearing. Even so, among the four towns studied in detail, it is still especially common in Bargas and Mocejon, existing in approximately a third of the old houses preserved. Besides, in many of the scarce new houses with its main access through such a front court which are built nowadays, this court is not anymore the enclosed patio of the local tradition, the kind of patio where the main door stayed open during daylight and was closed by night, but a little and almost non-existent space which entire enclosure allows looking inside, preventing its inhabitants from being able to adjust its privacy during the day, but facilitating the contemplation from the street of the main façade of the house. This practice is actually endorsed by the local building regulations. It has led to the arising in the urban centres of the whole region of a profusion of front courts fully open to the street, displacing the typical street sections and distorting to a great extent the perception of the public space. They are widely spread in the region, maybe as an epilogue to the domestic front courts traditionally giving access to the houses. However, once the privacy of such spaces has been lost by the suppression of the enclosing walls, they become purely representative features, hardly ever or never used, and often of exiguous size. They seem to have become a symbol of what they were, a remnant of a bluntly declining practice. In fact, commonly their owners garnish them with a myriad of domestic plants, the geranium reigning among them, as it seems to have always been. They become this way small blossoming gardens open to the street, keeping at least part of the memory of the green, refreshing and shaded front courts which could traditionally be grasped from the street through their front doors during the day time, while they stayed open.

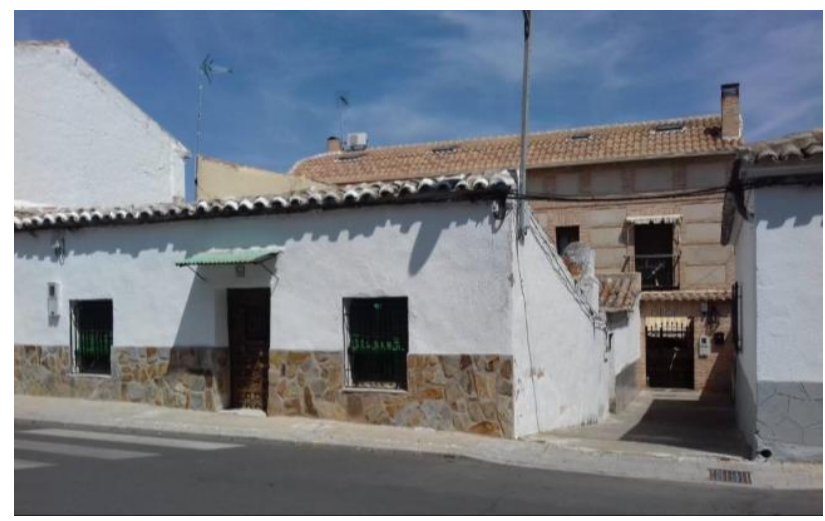

Figure 5. House in Olias del Rey originally accessed through its front enclosed patio and later on transformed to have a new door directly open to the street.

The most interesting result regarding the state of conservation is the nature of the buildings where different states of deterioration have been found, as once more it is directly linked to the social status perception of the diverse kinds of traditional houses. Contrasting the data on those humble buildings having only one floor with those counting on more floors, significant differences in their state of conservation are found. Being so, in all the four municipalities studied in detail the percentage of humble houses still being well preserved is under that of the large manors. And this divergence is even more substantial in the case of Olias del Rey, where only a $44 \%$ of the humble ones are well preserved, while they are a $68 \%$ among the richer ones. The same conclusions can be reached by comparing the proportion of them which are currently in ruins, being in all towns around a 10\% higher in the humble houses. Nowadays it is clearly more onerous and complex to rehabilitate the vast manors, for having multiple spaces primitively dedicated to livestock, storage and other farming functions, all of them hardly adaptable to the current use of the houses. In spite of it, the smaller houses tend to be more commonly abandoned, being more frequently in ruins, even when their adaptation to contemporary needs is easier and less expensive.

As for the specific data gathered on the historic houses, in all the four municipalities only approximately a tenth of the still kept old buildings have maintained practically all their traditional features. Hence from the already exiguous proportion of historic buildings which have survived (just a quarter of them) only a tenth of those have kept in a completely satisfactory way its traditional character. These data allow definitely quantifying and denouncing the magnitude of this unprecedented heritage catastrophe, perceptible at first glance, but not fully understood and assumed till facing it. Thereupon the majority of the few historic buildings having survived destruction and neglect have had their traditional features altered in diverse ways. The percentage of buildings where local traditional identity has been substantially kept is only slightly higher in the case of Olias del Rey. However, fortunately at least these identified alterations are in three fourths of the buildings affecting only some particular elements, generally some of their constructive details. Meanwhile, only in a tenth of the altered buildings there are significant general transformations, modifying also its volume, its composition or both.

As for the specific transformations found in their building details, the most interesting ones are those related to the most representative details of the buildings, those especially providing them with their character to the public realm: outer finishings and main entrances.

To begin with, traditional finishings are kept in approximately just a $5 \%$ of the historic buildings still kept, already relatively scarce by themselves, without hardly any new buildings showing such features, at least in its really traditional composition. This percentage is rather homogeneous in all the four towns studied in detail, being only slightly higher in both Bargas and Mocejon, and apparently similar in the rest of La Sagra. A wider deviation can be appreciated when comparing the situation of the finishings in the historic buildings considering the main façade position with regard to the public realm than considering the disparities in the way they are regulated in each different municipality. Thus in the historic buildings accessed from the traditional front court, this is those where the main façade is hidden from the street, for facing this enclosed court instead, the percentage of buildings which keep their traditional finishings is higher than in those buildings having their main façade facing the street, being accessed directly from it. The proportion of façades where nontraditional finishings are found is even double more common in those façades able to send a particular message to the public realm. This message might be the building owners are aware of the latest trends, they care for their property, periodically renovating it, or straightforwardly they do not lack the means to keep their house updated. Nevertheless, being most of the elements replacing the traditional ones successful or unsuccessful imitations of them, it seems clear the main message they intend to send must belong to the last groups of them. It is relatively irrelevant for the transformations occurring, in other words, the will to adapt the buildings to new trends or styles; while it is paramount the intent to show one's house is well kept and updated. Apart from it, the finishings which unsuccessfully pretend to imitate the traditional ones regularly try to simulate not the most humble ones, but the mixed masonries made of both bricks and rammed earth which were traditionally characteristic from the richest houses in La Sagra. 


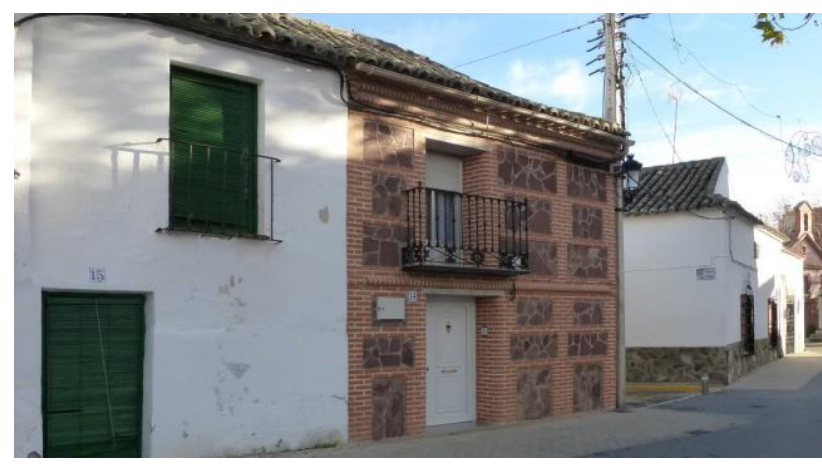

Figure 6. Traditional house in Numancia de la Sagra which was divided into two properties. One of them is still preserving its traditional features while another has been transformed to make it look like the richest traditional houses

With regard to the exterior openings, data were separately gathered for the main doors, the secondary doors (normally those accessing the garage or the walled backyard), and the windows, for being understandable, even prior to document all these elements, their diverse alteration processes which might be revealing. Thanks to this decision, interesting conclusions can be reached. One could suppose the exterior joinery of the historic buildings might have been replaced fundamentally for the changing functional requirements, such as seeking for a higher insulation, what it is actually prescribed by current national building codes. In fact, the proportion of the windows not drawing on local tradition found in new buildings is significantly higher than that of the main doors. This would be therefore coherent with a technical or functional origin for the progressive disappearance of the traditional openings. Nevertheless, the results found in the historic buildings show exactly the opposite, invalidating this assumption. In more than a third of the historic buildings of Magan, Bargas and Mocejon the windows joinery is still the traditional one, escalating to half of them in the case of Mocejon. Meanwhile, the proportion of traditional joinery kept in the main doors of the same historic buildings is around a $10 \%$ lower than that of the windows in all the four municipalities. This is once more the most representative element to the street is the most transformed one.

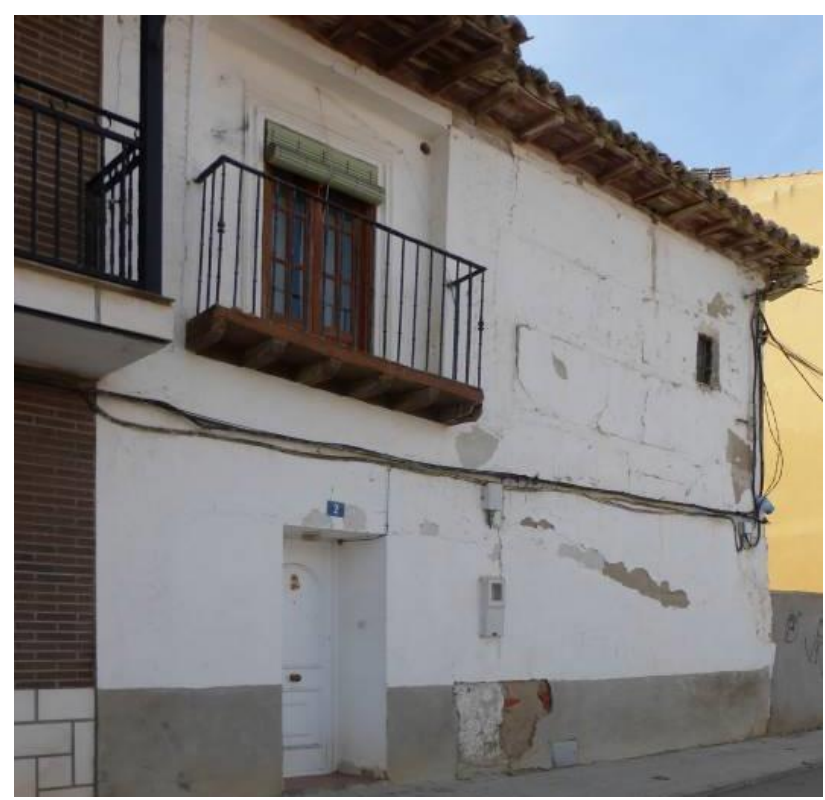

Figure 7. House in Magan where its traditional window is kept while the main door has been replaced.
At the same time, the best kept traditional building patterns in the historic buildings of all the four municipalities from those defining the urban landscape have proven to be precisely among the least superficial ones: cornices, roofs and the way the openings are shaped, apart from their very structure, which is kept in basically all the old buildings. In all these towns all these details are still traditional in most of their old buildings: from a $65 \%$ (Bargas, Magan) to an $85 \%$ (Mocejon) of the cornices, from a 65\% (Bargas, Olias del Rey, Magan) to an $80 \%$ (Mocejon) of the roofs, and from an $80 \%$ (Bargas) to a $95 \%$ (Magan) of the lintels of the openings. In those scarce cases where they have been replaced, it is unusual they are substituted by models totally foreign to local tradition, apart from some minor exceptions, as it is the case of the cornices in Magan or the roofs in Bargas and Magan, but never going beyond a $20 \%$.

Regarding the new buildings, the situation is not more promising. Different situations have been identified in the diverse municipalities studied in detail though, and the same can be observed by simply looking critically at La Sagra as a whole. The will to follow local patterns found in the new buildings of Bargas and Olias del Rey has proved to be very similar, while in those of Magan this will is slightly less prevailing and in the case of Mocejon, being also less common, this intention is more often transcending the mere incorporation of particular building details. Therefore it is in Magan where the will to keep local identity has been less significant in its new architecture, with Bargas and Olias del Rey showing better results. Once more it is precisely Magan the town which had a more rural or humble character right before these transformations started to operate. In any case, the determination to embed new buildings in the local tradition, and not the success in doing so, is in all the four towns strikingly similar and consequently can be assumed for La Sagra region as a whole. Independently of the outcome of this willingness, only a $23 \%$ of the new buildings in Bargas, Olias del Rey and Mocejon and a 29\% of those in Magan do not show any intent to respond in some way to local identity.

Besides, this proportion is not but growing in the last years. In less and less buildings no intent to incorporate at least some traditional patterns can be found, whatever results are achieved when doing so. Among the most recent buildings, those built after 2000, almost all of them seek for responding somehow to the tradition of this region. At the same time, however, gathered data show this will is noted in increasingly superficial features, progressively moving away from truly local models being imitated in them. The imitation of traditional patterns has been to a great extent replaced by an attempt to emulate other just allegedly local features, mostly following a kind of generic vernacular from Toledo in general, made of vulgarised copies of what is popularly considered to belong to this region.

Globally, without making any distinction between the transformations found in new and historic buildings, it is the historic centre of Olias del Rey the one keeping its traditional identity to a greater extent, followed, in this order, by Bargas, Mocejon, and Magan.

That said, are the existing local regulations causing the diverse situations found in each of them? Those from Olias del Rey are indeed the most meticulous with these aspects, though those from Bargas and Mocejon regulate them quite similarly. But, at the same time, if being the regulations the only determining factor for the situation found, the results in Bargas and Mocejon should be similar to each other, as their regulations are, and not so much those obtained in Bargas and Olias del Rey. The same is found through the detailed analysis of the aspects they regulate when 
compared to the most frequent transformations occurred in each town. Therefore we can conclude regulations contribute to the analysed transformation processes, but they cannot fully explain them, nor totally subdue them. At the same time, beyond their regulations, it is more meaningful to find Magan, the historically less urban town, to have ended up being the most altered one. And likewise the one having the historically highest proportion of large manors, Olias del Rey, has come to be the best preserved one as a whole. Thus the impact of this factor shows to be transcending the regulations, contributing even more than them to the on-going transformations in the traditional architecture of these municipalities.

\section{CONCLUSIONS}

The analysed results prove the scale of the transformation suffered by local traditional identity is unprecedented, and, with regard to some of its components, also well beyond what could initially be conjectured.

When observing a region such as La Sagra, an area similar to many other ones within the Spanish geography, one can understand, even if hardly knowing its past image, it has lost its particular character to a great extent. Besides, it is a representative case of the current situation in diverse regions, and its analysis enlightens how the urban landscape is being altered not only in the studied zone, but also in most of the country. The characteristic architecture of most of the selected towns has been often replaced by complexes of buildings which still keep resemblances to the unique character of this region, even if often decontextualized and adulterated. The perception of this character is stifled by a number of buildings in which only fragmented memories of it can be grasped, efforts often truncated and only rarely successful to keep it alive, coexisting with mockeries of what could be described as the most generic representation of what it is popularly understood as rural or vernacular.

The studied situation also proves local building regulations do play a role in mitigating at least part of the transformation processes studied here. They have an evident impact in most of the documented features. The more precise the regulations are in a municipality, the better is the outcome of their application. But, at the same time, it is even more notable the existence of alteration processes which are equally affecting the entire region and continue being unattainable through these regulations. This explains the similarity of most of the documented processes in every town, beyond any divergence coming from their respective local building regulations. This is, well defined regulations do prove to temper at least part of the problem, but in any case they do not suffice to tackle it in its entire extent. Their higher precision is being effective, as these results show, but they cannot control by themselves what they intend to revert. This highlights the importance of identifying the most successful local building regulations and trying to develop equivalent documents, always adapted to local conditions, for all other municipalities which are not yet renouncing to keep their unique local identity.

Listing and protecting specific buildings, selected among the many existing, may have saved some from demolition, though most of the listed houses are sadly heading to their progressive ruin by the lack of maintenance. Besides, if we compare the samples of buildings commonly listed with the vast number of them disappearing at the same time, it is easily inferred this by itself is not enough either in order to solve this problem.

That said, beyond the proven impact of the currently existing preservation tools, it is even more relevant what has been understood through this research on the nature of the on-going transformation processes which are being addressed by them in order to preserve local identity. Thus the deterioration of traditional local identity has proven to be, beyond any particular functional or technical alterations, a fundamentally cultural issue. Without understanding this, to adopt successful policies in this field would be complicated.

The factors having the most impact on the way our historic centres are being transformed are the way the social aspirations of the owners of the buildings are being mirrored in them, the models which are considered to be the richest or most respectable ones in the regional public imaginary, as well as those popularly assumed as being vernacular patterns, or the training and knowledge on those patterns of all the diverse agents involved in designing, constructing and maintaining the buildings, headed by the very architects.

Proving that, data such as those showing the façades of the traditional houses have been transformed to a greater extent when they can be seen from the public realm than when they stand facing a private court. Or those revealing the main changes occurred in the most humble houses are not addressed to make them look more modern or updated, but to make them look as similar as possible to the historically richer traditional houses, and doing so by trying to replicate their characteristic masonry, their iron grilles on the windows, etc. The same is portrayed by finding the most altered features in the historic houses are just their finishings and their main doors, this is those elements with a most significant representative role in the perception of the house from the street, while for the same reason cornices, roofs and, of course, the masonry structure are the least transformed features.

Besides, gathered data show the percentage of new buildings where a traditional image is being sought has not but grown in the last two decades, being found in many aspects in practically everything being lately built in the urban centres of this region. The interest in keeping local identity proves therefore to be practically general and, besides, to be continue growing. Nevertheless, the same data reflect this imitated tradition is commonly and progressively becoming less and less known, understood and mastered and, because of it, the outcome of that growing will to maintain it is increasingly estranged from the patterns it pretends to preserve.

If the interest is growing and, at the same time, the outcome is worsening, it seems to be evident a key factor in this issue is the need for deeper knowledge and study on the heritage we intend to preserve, and mostly and primarily a better training on this matter, not only for all agents involved in designing and building, but also for the owners, developers and the interested community as a whole.

\section{UPGRADE PROPOSALS}

If understanding the nature of the phenomena to be faced is an inescapable step to develop more efficient tools to tackle them, therefore the means which must be proposed for it must also be eminently cultural. Consequently, hereafter several measures are posed in order to contribute to revert or at least mitigate the progressive loss of local traditional identity with the best possible guarantees.

Apart from more precise regulations, based on a more rigorous study of local tradition, it would be necessary to implement the following measures: 
- Development of extensive, thorough and rigorous pattern books on the characteristic features of the building tradition from each town. They should be as visual as possible and include both pictures and dimensional drawings to be used as references. The documented patterns could then be both easily replicated and taken as the baseline for new designs drawing on them. These pattern books, in any case, would be totally useless without appropriately promoting them. They should always be freely and easily available for anyone interested in designing, building, commissioning, repairing or altering any building in the area they cover.

- Educational programs addressed not only to promote and recover the constructive and architectural traditions themselves, but also to counteract the existing prejudices on them both among the architecture and building practitioners and in the society as a whole. Without this type of measures, in fact, every other one would only have a limited impact. These prejudices are those frequently leading an architect or a builder, for instance, to directly discard the repair of a rammed earth wall just for being a rammed earth wall, opting for its demolition, or a building owner to cover that very wall with a ceramic veneer simulating it is a wall made of bricks. And these are also the prejudices leading to leave this matter aside or just superficially deal with it in the training of many of the agents involved in designing and constructing new buildings.

- Enhancement and promotion of local crafts people, at least from the public administrations, favouring them, besides, when assigning contracts and works, using the corresponding bidding documents in order to do so. These policies would mean an additional public investment, but they would also imply a positive effect on local economy in diverse ways, what would allow amortizing the required investment. Apart from it, such regulations as those previously proposed would also increase the demand for this kind of work. And this increase would undoubtedly, as the situation in other places proves, lead to the growth of the needed supply.

- Get the best from all new works or upgrades of existing buildings by the public administrations in order to create exemplary models for their respect to local tradition. These administrations cannot waste such opportunities to provide meaningful contemporary examples. If well designed and built, they would certainly become models widely imitated by private enterprise, which seems to be in such a need for such successful references. It cannot be expected from private entrepreneurs to successfully lead the preservation of local identity of the very public administrations which tries to force them to do so are not leading this effort.

In any case, and in spite of the amplitude of the analysed problems, working in at least one of these measures could itself make a big difference in reaching these aims. By now, most of the existing protective policies in Spain are focused on a single aspect of the studied problems: their consequences on the urban landscape. It is thus generally ignored the context which leads to the deterioration of that landscape and, mostly, and in a very striking way, the required carrier for the continuity of local tradition: the masters in the building crafts. To preserve local identity is sought with scarce exceptions. But, as a consequence of the lack of appropriate studies and tools to successfully tackle these problems and the ignorance of the authentic richness and adaptability of these traditions, this identity is progressively turned into a generic mockery of vernacular motifs. It is therefore urgent to continue also undertaking this kind of studies in order to progress in the preservation of a cultural richness which, to date, is still vanishing in front of us.

\section{REFERENCES}

Azorín, 1944, 2004: Con Cervantes. Alicante: Biblioteca Virtual Miguel de Cervantes.

Cervera Vera, L., 1998: Plazas mayores en la comarca toledana de La Sagra. Toledo: Real Academia de Bellas Artes y Ciencias Históricas de Toledo.

Feduchi, L., 1974 - 1984: Itinerarios de arquitectura popular española, 5 vol. Barcelona: Blume.

Flores, C., 1973 - 1977: Arquitectura popular española, 5 volumes. Madrid: Aguilar.

García Mercadal, F., 1930: La casa popular en España. Madrid: Espasa-Calpe.

Instituto de Patrimonio Cultural de España, 2014: Plan Nacional de Arquitectura Tradicional.

Oliver, P., 2006: Built to Meet Needs. Cultural Issues in Vernacular Architecture. Burlington, Massachusetts: Architectural Press, Elsevier.

Rapoport, A., 1969: House Form and Culture. Englewood Cliffs: Prentice-Hall.

Sánchez-Horneros Gómez, A., 1981: La arquitectura popular toledana. Colección Temas Toledanos. Toledo: Publicaciones del IPIET, Diputación Provincial de Toledo.

Torres Balbás, Leopoldo. 1933. La vivienda popular en España. Folklore y Costumbres de España, $3^{\text {rd }}$ volume, 137-502. Madrid: Ediciones Merino. 